\title{
EXISTENCE OF SOLUTIONS FOR A CLASS OF VARIATIONAL INEQUALITIES
}

\author{
Taallah Frekh
}

Department of Mathematics, Faculty of Science, Badji Mokhtar University, Annaba, Algeria

Received 2013-10-26; Revised 2013-11-09; Accepted 2013-12-09

\section{ABSTRACT}

In this study we considered a deformed elastic solid with a unilateral contact of a rigid body. We studied the existence, uniqueness and continuity of the deformation of this solid with respect to the data. We proved the existence of solutions for a class of variational inequalities.

Keywords: Variational Inequalities, Unilateral Contact

\section{INTRODUCTION}

Several problems in mechanics, physics, control and those dealing with contacts, lead to the study of systems of variational inequalities.

This model has been studied by Slimane et al. (2004); Bernardi et al. (2004); Brezis (1983); Brezis and Stampacchia (1968); Ciarlet (1978); Grisvard (1985); Haslinger et al. (1996); Lions and Stampacchia (1967).

We consider a solid occupying an open bounded domain $\Omega$ of a sufficiently regular boundary $\Gamma=\partial \Omega$ with unilateral contact with a rigid obstacle.

\section{Theorem 1.1}

Let $\mathrm{P} \in \mathrm{L}^{2}\left(\Omega \mathrm{R}^{3}\right)$ be the resulting of force density. Then there exists a unique solution for the variational problem: find $\mathrm{u} \in \mathrm{V}$ such that:

$$
\mathrm{a}(\mathrm{u}, \mathrm{v})=1(\mathrm{v}), \forall \mathrm{v} \in \mathrm{V}
$$

With:

$$
\mathrm{V}=\left\{\mathrm{v} \in \mathrm{H}_{0}^{1}\left(\Omega, \mathrm{R}^{3}\right)\right\}
$$

$\mathrm{a}(\mathrm{u}, \mathrm{v})=$ The bilinear form

$\mathrm{l}(\mathrm{v})=$ The linear form

To prove this theorem we make use of the Lax-Milgram which is based on proving the continuity and V-ellipticity of the bilinear form $\mathrm{a}(\mathrm{u}, \mathrm{v})$ and the continuity of $\mathrm{l}(\mathrm{v})$.

\section{FORMULATION OF THE CONTACT PROBLEM}

Here we consider a solid occupying an open bounded domain $\Omega$ of a sufficiently regular boundary $\Gamma=\partial \Omega$.

The solid is supposed to have:

- A density on the volume, of force $\mathrm{P}$ in $\Omega$

- Homogenous boundary conditions on $\Gamma$

- Unilateral contact with a rigid obstacle of equation $\mathrm{x}_{3}=0$ on contact surface $\Omega_{\mathrm{c}}=\Omega / \Gamma$.

The displacement is given by:

$$
(\mathrm{u}(\mathrm{x})) \cdot \mathrm{e}_{3} \geq 0 \text {, in } \Omega_{\mathrm{c}}
$$

With $\left(e_{1}, e_{2}, e_{3}\right)$ Cartesian base we denote by $\eta$ the reaction of the obstacle on the solid. The relations leading to a unilateral contact (without friction) are given by:

$$
\left\{\begin{array}{l}
(u(x)) \cdot e_{3} \geq 0, \text { in } \Omega_{c} \\
(\eta) \cdot e_{3} \geq 0, \text { in } \Omega_{c} \\
(u(x) \eta) \cdot e_{3}=0, \text { in } \Omega_{c}
\end{array}\right.
$$

We use the space $\mathrm{H}_{0}^{1}\left(\Omega, \mathrm{R}^{3}\right)$ of functions in $\mathrm{H}^{1}(\Omega$, $\mathrm{R}^{3}$ ) equals to zero on $\Gamma$.

Let us introduce the convex subspace $\mathrm{K}$ for the authorized displacements, to be defined as: 


$$
\mathrm{K}=\left\{\mathrm{v} \in \mathrm{H}_{0}^{1}\left(\Omega, \mathrm{R}^{3}\right),(\mathrm{v}) \cdot \mathrm{e}_{3} \geq 0, \text { in } \Omega_{\mathrm{c}}\right\}
$$

We consider the following variationnal formulation Find:

$$
(\mathrm{u}, \eta) \in \mathrm{H}_{0}^{1}\left(\Omega, \mathrm{R}^{3}\right) \times \mathrm{H}^{-1}(\Omega)
$$

Such that:

$$
\left(\mathrm{P}_{\mathrm{e}}\right) \mathrm{a}(\mathrm{u}, \mathrm{v})-\mathrm{c}(\eta, \mathrm{v})=1(\mathrm{v}), \quad \forall \mathrm{v} \in \mathrm{H}_{0}^{1}\left(\Omega, \mathrm{R}^{3}\right)
$$

With:

$$
\mathrm{c}(\eta, \mathrm{v})=\int_{\Omega_{\mathrm{c}}} \eta \mathrm{vdx}
$$

And the reduced problem becomes:

Find $\mathrm{u} \in \mathrm{K}$ such that:

$$
\left(P_{I}\right)\left\{\begin{array}{r}
a(u, v-u) \geq \\
1(v-u)
\end{array}\right.
$$

\section{Theorem 2.1}

For any solution $(\mathrm{u}, \eta)$ of problem $\left(\mathrm{P}_{\mathrm{e}}\right), \mathrm{u}$ is a solution of problem $\left(\mathrm{P}_{\mathrm{I}}\right)$.

\section{Proof}

Let $(\mathrm{u}, \eta)$ be a solution of problem $\left(\mathrm{P}_{\mathrm{e}}\right)$ and $\mathrm{u} \in \mathrm{K}$, $\forall \mathrm{v} \in \mathrm{K}$ and we have:

$$
\langle\eta, v\rangle \geq 0 \Leftrightarrow-\langle\eta, v\rangle \leq 0
$$

Problem $\left(\mathrm{P}_{\mathrm{e}}\right)$ leads to:

$$
\langle\chi-\eta, \mathrm{u}\rangle \geq 0, \forall \chi \in \mathrm{K}
$$

We assume that $\mathrm{x}=0$ :

$$
-\langle\eta, u\rangle \geq 0 \Leftrightarrow\langle\eta, u\rangle \leq 0
$$

By replacing $\mathrm{v}$ by $\mathrm{v}-\mathrm{u}$ in line one of problem $\left(\mathrm{P}_{\mathrm{e}}\right)$, we get:

$$
a(u, v-u)-c(\eta, v-u)=1(v-u)
$$

Where:

$$
\begin{aligned}
& -c(\eta, v-u)=-\langle\eta, v-u\rangle=-\langle\eta, v\rangle+\langle\eta, u\rangle \leq 0 \\
& \Rightarrow a(u, v-u) \geq 1(v-u), \forall v \in K
\end{aligned}
$$

Let $u$ be a solution of problem $\left(\mathrm{P}_{\mathrm{I}}\right)$ then $(\mathrm{u}, \eta)$ is a solution of $\left(\mathrm{P}_{\mathrm{e}}\right)$ :

$$
\mathrm{a}(\mathrm{u}, \mathrm{v}-\mathrm{u})-\mathrm{l}(\mathrm{v}-\mathrm{u}) \geq 0, \forall \mathrm{v} \in \mathrm{K}
$$

By using Green's formula, we get:

$$
\mathrm{a}(\mathrm{u}, \mathrm{v}-\mathrm{u})-\langle\eta, \mathrm{v}-\mathrm{u}\rangle-\mathrm{l}(\mathrm{v}-\mathrm{u}) \geq 0
$$

We assume that $\mathrm{v}=\mathrm{i} \pm \varphi$, with $\varphi \in \mathrm{D}\left(\Omega \mathrm{R}^{3}\right)$, (i.e., $\varphi$ is of a compact support), then the integral on the contour is zero:

$$
\mathrm{a}(\mathrm{u}, \phi)=1(\phi), \forall \phi
$$

The integral on a contact area leads to:

$$
\langle\eta, \mathrm{v}-\mathrm{u}\rangle \geq 0, \forall \mathrm{v} \in \mathrm{K}
$$

By assuming that:

$$
\left\{\begin{array}{l}
v=0 \\
v=2 u
\end{array} \quad \Rightarrow\langle\eta, u\rangle=0\right.
$$

And with the property of convexity of $\mathrm{K}$, we get:

$$
\langle\chi-\eta, \mathrm{u}\rangle=0\langle\chi, \mathrm{u}\rangle-\langle\eta, \mathrm{u}\rangle=\langle\chi, \mathrm{u}\rangle \geq 0
$$

\section{Theorem 2.2}

For any $\mathrm{P} \in \mathrm{H}^{-1}\left(\Omega, \mathrm{R}^{3}\right)$, the problem $\left(\mathrm{P}_{\mathrm{e}}\right)$ has a unique solution $(\mathrm{u}, \eta) \in \mathrm{H}_{0}{ }^{1}\left(\Omega \mathrm{R}^{3}\right) \times \mathrm{H}^{-1}(\Omega)$

\section{Proof}

The existence of the solution $\mathrm{u}$ of problem is a direct application of Slimane et al. (2004).

Let us consider:

$$
\mathrm{L}(\mathrm{v})=\mathrm{a}(\mathrm{u}, \mathrm{v})-\mathrm{l}(\mathrm{v})
$$

\section{Remark}

In problem $\left(\mathrm{P}_{\mathrm{I}}\right)$, we have:

- if $\mathrm{v}=0$, then:

$$
-\mathrm{a}(\mathrm{u}, \mathrm{u}) \geq-\mathrm{l}(\mathrm{u})
$$

- if $v=2 u$, then: 


$$
\mathrm{a}(\mathrm{u}, \mathrm{u}) \geq \mathrm{l}(\mathrm{u}) \Rightarrow \mathrm{L}(\mathrm{u})=0
$$

The Ker of the form $(\eta, v)$ is characterized by:

$$
\mathrm{V}=\left\{\mathrm{v} \in \mathrm{H}_{0}^{1}\left(\Omega, \mathrm{R}^{3}\right),{\mathrm{u} . \mathrm{e}_{3}}=0, \text { in } \Omega\right\}
$$

Let $\mathrm{v} \in \mathrm{V}$, then $\mathrm{v}$ and $-\mathrm{v}$ are in $\mathrm{K}$ from the problem $\left(\mathrm{P}_{\mathrm{I}}\right)$ and $\mathrm{L}(\mathrm{u})=0$, we have:

$$
\begin{aligned}
& a(u, v)-a(u, u)+b(v, \lambda)-1(v)+1(u) \geq 0 \\
& -1(v)+1(u) \geq 0 \Leftrightarrow a(u, v)-1(v)-a(u, u) \\
& -1(u) \geq 0 \Leftrightarrow a(u, v)-1(v) \geq 0 \Rightarrow L(u)=0
\end{aligned}
$$

We remplace $v$ by $-\mathrm{v}$ in $\mathrm{L}(\mathrm{u})$ to get:

$$
\begin{aligned}
& \mathrm{a}(\mathrm{u}, \mathrm{v})-\mathrm{l}(-\mathrm{v}) \geq 0 \Leftrightarrow-\mathrm{a}(\mathrm{u}, \mathrm{v})+\mathrm{l}(\mathrm{v}) \geq 0 \\
& \Leftrightarrow \mathrm{a}(\mathrm{u}, \mathrm{v})-\mathrm{l}(\mathrm{v}) \leq 0 \Leftrightarrow \mathrm{L}(\mathrm{u})=0
\end{aligned}
$$

$\mathrm{L}$ is of a compact support in $\mathrm{V}$ and from the following inf-sup condition:

$$
\sup \frac{\langle\eta, \mathrm{v}\rangle}{\|\mathrm{v}\|} \geq \beta\|\eta\|_{\mathrm{H}^{-1}}
$$

We can prove that there exists $\eta \in \mathrm{H}^{-1}(\Omega)$.

Then $(\mathrm{u}, \eta)$ satisfies line one of problem $\left(\mathrm{P}_{\mathrm{e}}\right)$.

The definition of $\mathrm{K}$ and $\mathrm{L}(\mathrm{u})=0$, leads to:

$$
\langle\chi-\eta, \mathrm{u}\rangle=\langle\chi, \mathrm{u}\rangle-\langle\eta, \mathrm{u}\rangle=\langle\chi, \mathrm{u}\rangle \geq 0, \quad \forall \chi \in \mathrm{K}
$$

This proves the existence of the solution.

Let $\mathrm{U}_{1}$ and $\mathrm{U}_{2}$ be two solutions of problem $\left(\mathrm{P}_{\mathrm{I}}\right)$. With $\mathrm{U}_{1}=\mathrm{u}_{1}$ and $\mathrm{U}_{2}=\mathrm{u}_{2}$ then:

$$
\begin{aligned}
& \mathrm{a}\left(\mathrm{U}_{1}, \mathrm{~W}-\mathrm{U}_{1}\right) \geq \mathrm{l}\left(\mathrm{W}-\mathrm{U}_{1}\right), \forall \mathrm{W} \in \mathrm{K} \\
& \mathrm{a}\left(\mathrm{U}_{2}, \mathrm{~W}-\mathrm{U}_{2}\right) \geq \mathrm{l}\left(\mathrm{W}-\mathrm{U}_{2}\right), \forall \mathrm{W} \in \mathrm{K}
\end{aligned}
$$

By adding that $\mathrm{W}=\mathrm{U}_{2}$ and $\mathrm{W}=\mathrm{U}_{1}$ we have:

$$
\begin{aligned}
& a\left(U_{1}, U_{2}-U_{1}\right) \geq 1\left(U_{2}-U_{1}\right) a\left(U_{2}, U_{1}-U_{2}\right)+b\left(U_{1}-U_{2}, \lambda\right) \\
& \geq 1\left(U_{1}-U_{2}\right) \Leftrightarrow a\left(U_{1}, U_{1}-U_{2}\right) \geq 1\left(U_{1}-U_{2}\right) \\
& a\left(U_{2}, U_{1}-U_{2}\right) \geq 1\left(U_{1}-U_{2}\right)
\end{aligned}
$$

$$
\begin{aligned}
& \mathrm{a}\left(\mathrm{U}_{1}-\mathrm{U}_{2}, \mathrm{U}_{1}-\mathrm{U}_{2}\right) \leq 0 \\
& \Leftrightarrow \mathrm{a}\left(\mathrm{U}_{1}-\mathrm{U}_{2}, \mathrm{U}_{1}-\mathrm{U}_{2}\right) \leq 0 \\
& \Leftrightarrow \alpha\left\|\mathrm{U}_{1}-\mathrm{U}_{2}\right\|^{2} \leq 0 \Leftrightarrow \mathrm{U}_{1}=\mathrm{U}_{2}
\end{aligned}
$$

By the inf-sup condition of problem $\left(\mathrm{P}_{\mathrm{e}}\right)$ gives us:

$$
\forall \mathrm{v} \in \mathrm{H}_{0}^{1}\left(\Omega, \mathrm{R}^{3}\right),\left\langle\eta_{1}, \mathrm{v}\right\rangle=\left\langle\eta_{2}, \mathrm{v}\right\rangle \Leftrightarrow \eta_{1}=\eta_{2}
$$

\section{THE DISCRETE PROBLEM}

We introduce a discrete subspace $\mathrm{V}_{\mathrm{h}}$ of $\mathrm{V}$ such that:

$$
\mathrm{V}_{\mathrm{h}}=\left\{\mathrm{v}_{\mathrm{h}} \in \mathrm{C}\left(\Omega, \mathrm{R}^{3}\right), \mathrm{v}_{\mathrm{h}} \in \mathrm{P}_{1}(\mathrm{k}) \mathrm{v}_{\mathrm{h}}=0, \text { on } \partial \Omega\right\}
$$

And $\operatorname{dim} \mathrm{V}_{\mathrm{h}}<\infty$, therefore there exists a basis: $\left\{\omega_{\mathrm{i}}\right\}, \mathrm{I}$ $=1$ to $\mathrm{N}_{\mathrm{h}}$, we can then write:

$$
\mathrm{v}_{\mathrm{h}}=\sum_{\mathrm{i}=1}^{\mathrm{N}_{\mathrm{h}}} \beta_{\mathrm{i}} \omega_{\mathrm{i}}
$$

Now, let us construct a closed convex subset $K_{h}$ of $V_{h}$ such that $K_{h}$ should be reduced to a finite number of constraints on the $\beta_{\mathrm{i}}$ :

$$
\mathrm{K}_{\mathrm{h}}=\left\{\begin{array}{l}
\mathrm{v}_{\mathrm{h}} \in \mathrm{V}_{\mathrm{h}}, \text { v. }_{3} \geq \varphi \\
\text { at every vertex of each triangle } \mathrm{K}
\end{array}\right\}
$$

Then $\mathrm{K}_{\mathrm{h}} \subset \mathrm{K}$ and $\mathrm{K}_{\mathrm{h}} \subset \mathrm{V}_{\mathrm{h}}$.

We remark that problem $\left(\mathrm{P}_{\mathrm{I}}\right)$ is equivalent to find $\mathrm{u}_{\mathrm{h}} \in \mathrm{K}_{\mathrm{h}}$ such that:

$$
\left(\mathrm{P}_{\mathrm{h}}\right) \mathrm{a}\left(\mathrm{u}_{\mathrm{h}}, \mathrm{v}_{\mathrm{h}}-\mathrm{u}_{\mathrm{h}}\right) \geq \mathrm{l}\left(\mathrm{v}_{\mathrm{h}}-\mathrm{u}_{\mathrm{h}}\right), \forall \mathrm{v}_{\mathrm{h}} \in \mathrm{K}_{\mathrm{h}}
$$

We assume $\mathrm{U}=\mathrm{u}$ and $\mathrm{W}=\mathrm{v}$.

\section{Theorem 3.1}

Let $U$ and $U_{k}$ be the solutions of problems $\left(P_{I}\right)$ and $\left(\mathrm{P}_{\mathrm{h}}\right)$, respectively. Let us denote by $\mathrm{A} \in \mathrm{L}\left(\mathrm{V}, \mathrm{V}^{\prime}\right)$ the map defined, by $\mathrm{a}(\mathrm{U}, \mathrm{W})=(\mathrm{AU}, \mathrm{W})$, then:

$$
\left\|\mathrm{U}-\mathrm{U}_{\mathrm{h}}\right\|_{\mathrm{V}}=\left[\begin{array}{l}
\frac{\mathrm{M}^{2}}{\alpha^{2}}\left\|\mathrm{U}-\mathrm{W}_{\mathrm{h}}\right\|_{\mathrm{V}}^{2}+\frac{1}{\alpha} \\
\|\mathrm{P}-\mathrm{AU}\|_{\mathrm{V}^{\prime}} \\
\left\|\mathrm{U}-\mathrm{W}_{\mathrm{h}}\right\|_{\mathrm{V}}+\left\|\mathrm{U}_{\mathrm{h}}-\mathrm{W}\right\|_{\mathrm{V}}
\end{array}\right]^{\frac{1}{2}}
$$


With $\mathrm{P}$ is the resultant of the volume force.

\section{Proof}

By the definitions of $\mathrm{U}$ and $\mathrm{W}$, we have:

$$
\begin{aligned}
& \mathrm{a}(\mathrm{U}, \mathrm{U}-\mathrm{W}) \leq(\mathrm{P}, \mathrm{U}-\mathrm{W}), \\
& \forall \mathrm{W} \in \mathrm{Ka}\left(\mathrm{U}_{\mathrm{h}}, \mathrm{U}_{\mathrm{h}}-\mathrm{W}_{\mathrm{h}}\right) \leq\left(\mathrm{P}, \mathrm{U}_{\mathrm{h}}-\mathrm{W}_{\mathrm{h}}\right), \forall \mathrm{W}_{\mathrm{h}} \in \mathrm{K}_{\mathrm{h}}
\end{aligned}
$$

By adding these inequalities and transposing terms, we obtain:

$$
\begin{aligned}
& \mathrm{a}(\mathrm{U}, \mathrm{U})+\mathrm{a}\left(\mathrm{U}_{\mathrm{h}}, \mathrm{U}_{\mathrm{h}}\right) \leq(\mathrm{P}, \mathrm{U}-\mathrm{W}) \\
& +\left(\mathrm{P}, \mathrm{U}_{\mathrm{h}}-\mathrm{W}_{\mathrm{h}}\right)+\mathrm{a}(\mathrm{U}, \mathrm{W})+\mathrm{a}\left(\mathrm{U}_{\mathrm{h}}, \mathrm{W}_{\mathrm{h}}\right)
\end{aligned}
$$

By subtracting $a\left(U, U_{h}\right)+a\left(U_{h}, U\right)$ from both sides and grouping terms and by using the continuity and the coercively of the bilinear form $a(U, W)$, we deduce:

$$
\alpha\left\|\mathrm{U}-\mathrm{U}_{\mathrm{h}}\right\|_{\mathrm{V}}{ }^{2} \leq\left[\begin{array}{c}
\|\mathrm{P}-\mathrm{AU}\|_{\mathrm{V}^{\prime}}\left\|\mathrm{U}-\mathrm{W}_{\mathrm{h}}\right\|_{\mathrm{V}} \\
+\|\mathrm{P}-\mathrm{AU}\|_{\mathrm{V}^{\prime}}\left\|\mathrm{U}_{\mathrm{h}}-\mathrm{W}\right\|_{\mathrm{V}} \\
+\mathrm{M}\left\|\mathrm{U}-\mathrm{U}_{\mathrm{h}}\right\|_{\mathrm{V}}\left\|\mathrm{U}-\mathrm{W}_{\mathrm{h}}\right\|_{\mathrm{V}}
\end{array}\right]
$$

Since:

$$
\mathrm{M}\left\|\mathrm{U}-\mathrm{U}_{\mathrm{h}}\right\|\left\|\mathrm{U}-\mathrm{W}_{\mathrm{h}}\right\| \leq \frac{\mathrm{M}}{\alpha}\left\|\mathrm{U}-\mathrm{W}_{\mathrm{h}}\right\|^{2}
$$

We obtain:

$$
\begin{gathered}
\left\|\mathrm{U}-\mathrm{U}_{\mathrm{h}}\right\|_{\mathrm{V}}=\left[\begin{array}{l}
\frac{\mathrm{M}^{2}}{\alpha^{2}}\left\|\mathrm{U}-\mathrm{W}_{\mathrm{h}}\right\|_{\mathrm{V}}^{2}+\frac{1}{\alpha}\|\mathrm{P}-\mathrm{AU}\|_{\mathrm{V}^{\prime}} \\
\left\|\mathrm{U}-\mathrm{W}_{\mathrm{h}}\right\|_{\mathrm{V}}+\left\|\mathrm{U}_{\mathrm{h}}-\mathrm{W}\right\|_{\mathrm{V}}
\end{array}\right]^{\frac{1}{2}} \\
\forall \mathrm{W} \in \mathrm{K} \text { and } \forall \mathrm{W}_{\mathrm{h}} \in \mathrm{K}_{\mathrm{h}}
\end{gathered}
$$

\section{NUMERICAL RESULTS}

Consider elastic plate with the undeformed rectangle shape $(0,10) \times(0,2)$. The body force is the gravity force $f$ and the boundary force $g$ is zero on lower and upper side. On the two vertical sides of the beam are fixed (Fig. 1-3).

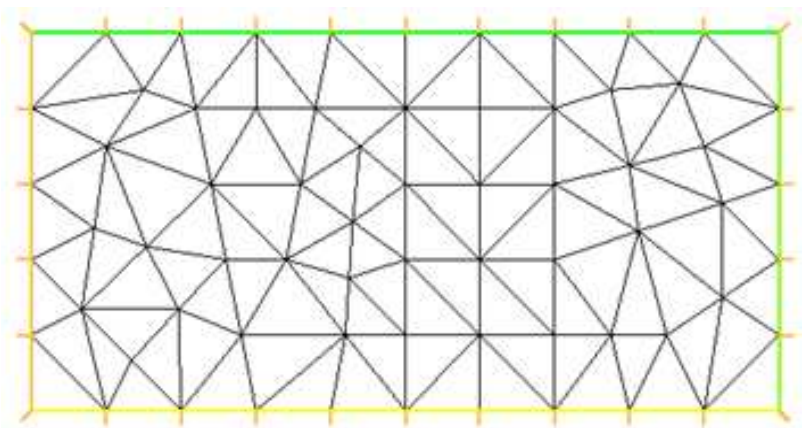

Fig. 1. Mesh

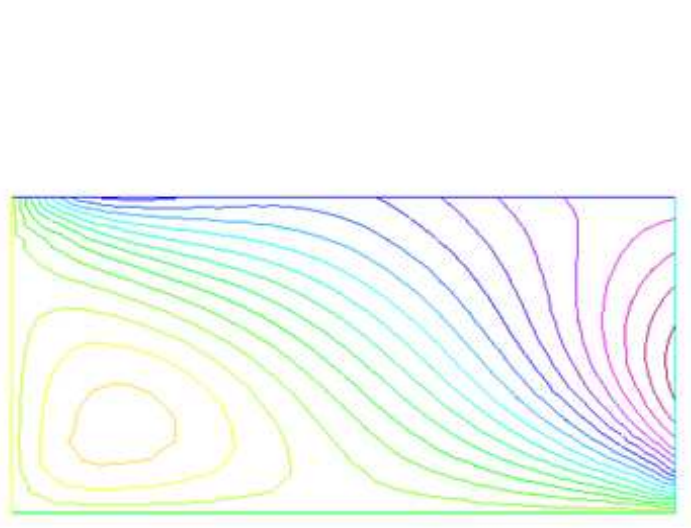

Fig. 2. Isovalue of deplacement $u_{x}$

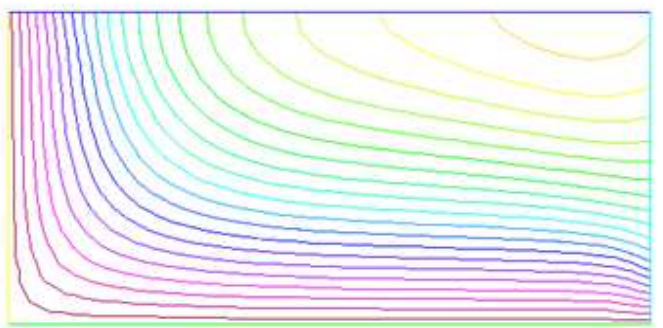

Fig. 3. Isovalue of deplacement $u_{y}$

\section{CONCLUSION}

By starting with the classical model for a deformed elastic solid with a unilateral contact of a rigid body, we 
proved the existence of solutions for a class of variational inequalities.

\section{REFERENCES}

Bernardi, C., Y. Maday and F. Rapetti, 2004. Discrétisations Variationnelles De Problèmes Aux Limites Elliptiques. 3rd Edn., Mathématiques et Applications, Springer, ISBN-10: 3540213694, pp: 312.

Brezis, H. and G. Stampacchia, 1968. Sur la régularité de la solution d'inéquations elliptiques. Bull. Soc. Math. France, 96: 153-180.

Brezis, H., 1983. Analyse fonctionnelle, Collection Mathématiques Appliquées pour la Maîtrise.

Ciarlet, P.G., 1978. The Finite Element Method for Elliptic Problems. 1st Edn., North-Holland, Amsterdam, New-York, Oxford, ISBN-10: 0444850287, pp: 530.
Grisvard, P., 1985. Elliptic Problems in Nonsmooth Domains. 1st Edn., SIAM, Philadelphia, ISBN-10: 1611972035, pp: 410.

Haslinger, J., I. Hlavacek and J. Necas, 1996. Numerical methods for unilateral problems in solid mechanics. Handbook Numer. Anal., 4: 313-485.

Lions, J.L. and G. Stampacchia, 1967. Variational inequalities. Comm. Pure Appl. Math., 20: 493-519. DOI: $10.1002 / \mathrm{cpa} .3160200302$

Slimane, L., A. Bendali and P. Laborde, 2004. Mixed formulations for a class of variational inequalities. Model. Math. Anal. Numer., 38: 177-201. DOI: 10.1051/m2an:2004009 